Carpe, Inma.

Artista de desarrollo visual.

Profesora de animación e investigadora en VIA University College/ The Animation Workshop, Animated Learning $L A B$.

Garcia Rams, M. Susana.

Artista audiovisual.

Doctora en Bellas Artes.

Directora del Master de Arteterapia.

Miembro del Grupo de Investigación Arte e industria y del IDECART (Instituto para la Investigación, desarrollo y difusión de los procesos de creación y arteterapia).

Profesora de animación en el Departamento de Dibujo en la UPV.

\title{
Animación: medio de reflexión y re-creación de realidades im-posibles.
}

TIPO DE TRABAJO:

Comunicación.

PALABRAS CLAVE

Animación, neurociencia cognitiva, percepción visual, realidad virtual, mediación artística.

KEY WORDS

Animation, cognitive neuroscience, visual perception, virtual reality, artistic mediation.

\section{RESUMEN}

La relación entre animación y realidad virtual va más allá de la aplicación de técnicas o softwares, que ayudan a producir video juegos, comerciales o películas. La mayoría de estudios sobre realidad virtual que encontramos en resúmenes de conferencias o revistas científicas, de las que la animación forma parte, como International Journal of Computer Graphics \& Animation, se basan en la tecnología; dejando a un lado el potencial que la animación ofrece como medio ilimitado de trabajar la creatividad; donde gracias a su plasticidad, plasma lo imposible como posible. Desde el Animated LAB, la UPV, las ciencias de la educación y la creación artística, queremos exponer: cómo la animación es un medio de reflexión por el que podemos aprender a Re-observar y percibir el mundo exterior para imaginar otros nuevos. Creamos y RE- creamos ficciones, que nuestro cerebro produce como realidades, que pueden provocarnos las mayores alegrías o peores pesadillas. Trabajamos a partir de producciones audiovisuales, entendiendo el funcionamiento del cerebro humano en lo que respecta a percepción, sinestesia y creación de imágenes e historias. De este modo, relacionamos la animación con la neurociencia cognitiva y afectiva, fomentando el uso de storytelling para reflexionar sobre situaciones que nos conmueven. Partimos del entendimiento de la realidad virtual como la creación abstracta a través de la que aprendemos a ser conscientes de nuestra realidad y emociones, así como a entreabrir las puertas a lo inconsciente. Por ello, es importante profundizar en los efectos del uso de la animación como método de mediación, ya que puede ayudar en terapias cognitivas y mejorar la calidad de nuestras vidas. La realidad se construye a través de nuestra percepción: las imágenes generan mundos (in)creíbles, situándonos al borde del abismo entre ficción y realidad, quizá encontremos tantas realidades virtuales como mentes que las generen, fuera y dentro de la pantalla. 


\section{ABSTRACT}

The relationship between animation and virtual reality goes beyond applying techniques or softwares, which help to produce video games, commercials o movies. Most studies of virtual reality found in abstracts' conferences or scientific journals, where animation is part of, like International Journal of Computer Graphics \& Animation, rely on technology; leaving aside the potential that animation offers as unlimited media to work creativity; thanks to its plasticity, it makes the impossible, possible. From Animated $\angle A B$, the UPV, the education science and artistic creation, we want to expose: how animation is a media of reflection by which we can learn to re-observe and perceive the outside world to imagine new ones. We create and re-create fictions, which our brain produces as realities that can provoke the greatest joys or the worst nightmares. We work from audiovisual production, understanding how the human brain when is related to perception, synesthesia and creating images and stories. Thus, we connect animation to cognitive and affective neuroscience, encouraging the use of storytelling to reflect on situations that move us. We understand virtual reality as the abstract creation through which we learn to be aware of our reality and emotions as well as to partially open the door to the unconscious. Therefore, it is important to look into the effects of the use of animation as a method of mediation, as it can help in cognitive therapies and improve the quality of our lives. The reality is constructed by our perception: Images generate in-credible worlds, placing the brink between fiction and reality; we may find as many virtual realities as many minds can generate them, on and off the screen.

\section{INTRODUCCIÓN}

...Y si existiera un lugar...un lugar secreto...donde nada es imposible? Un lugar milagroso... donde realmente pudieras cambiar el mundo?. Quieres ir?

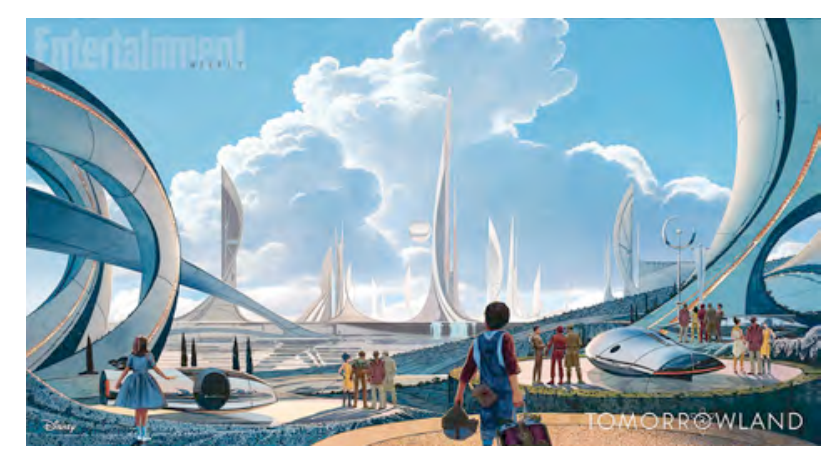

Ilustración 1. Concept art. "Tomorrowland".Disney, 2015. [on line] http://www.tomorrowlandmovie.com/uploads/images/Gallery/Official-Tomorrowland-Movie-Images/Tomorrowland-Syd-Mead-Concept-Art.jpg

Una invitación irresistible a todo aquel que alguna vez haya soñado con vivir en otros mundos.

Las películas animadas mezclan realidad y ficción transportándonos a increíbles universos que nunca hubiéramos imaginado. La imaginación es el gran tesoro que la mente humana dispone para crear esos universos paralelos donde vivir nuevas experiencias llenas de emoción y aventura. Mundos imposibles a los que el hombre quiere escapar huyendo de la monotonía, como Alice in Wonderland, (2010, Tim Burton). El mundo de la animación nos lleva a ese espacio donde lo imposible es posible, gracias a la imaginación y mecanismos que el cerebro humano tiene para entender lo que ve y (re)crearlo en sugerentes imágenes o historias. Las películas son una realidad (virtual) en movimiento, como la vida misma; en este sentido "somos creadores de nuestra propia realidad" (Dispenza, J. $2015 ; 54)$. Este artículo presenta la animación como medio de expresión artística por el que aprendemos a percibir "realidades", facilitadoras para crear otras, que nos ayudan a comprender el mundo en que vivimos. La verdadera "fábrica de sueños" no está en Hollywood, no es el cine, sino nuestro cerebro. 


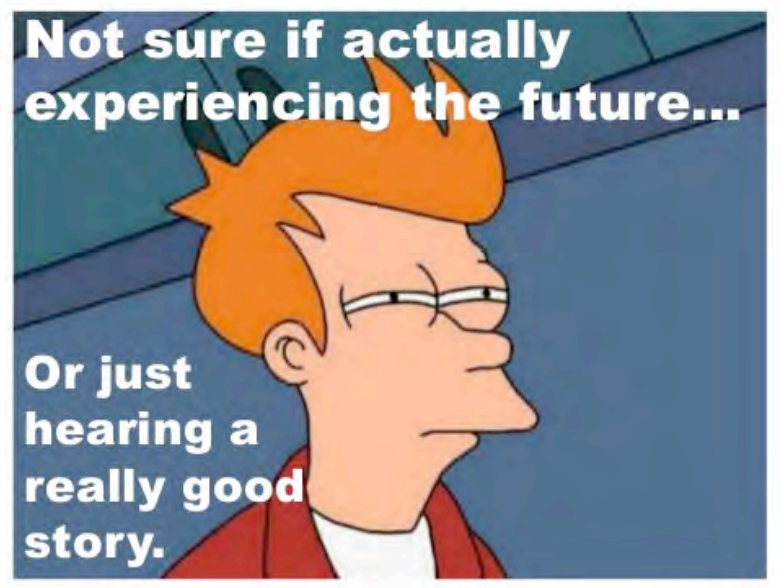

\section{Ilustración 2. Fan Art. Frame "Futurama".Groening, Matt. Fox (1999-2003)}

Son numerosos los estudios y artículos sobre realidad virtual, animación y nuevas tecnologías, no negamos su vital importancia como herramientas que apoyan al medio junto al pensamiento; pero la realidad virtual se puede entender más allá de nuevos softwares y aparatos que reinventan las visiones que en un primer lugar, no olvidemos, se originaron en nuestras mentes. Técnicas como la rotoscopia o motion capture son intentos de recrear el movimiento de la vida real dentro de nuevos espacios virtuales, ya sean películas como video juegos. Esta re-creación es de lo que en un principio ocuparon los pioneros del cine, G. Melies o S. Chomon, que idearon un puente mágico entre realidad y virtualidad a través de la animación; trasladando experiencias ciertas o imaginadas a un escenario nuevo a través de objetos y personajes. No es de extrañar que fuera Antonin Artaud quien acuñó el término réalité virtuelle: "la realidad en la que los objetos y las imágenes asumen la fuerza fantasmagórica de los dramas internos de la alquimia" (Artaud J. 0000; año y página 00). Hoy en día si nombramos realidad virtual, casi de inmediato la vinculamos con ciencia ficción, en especial en películas clásicas como Blade Runner (Ridley Scott, 1982) , series como Star Treck (1966-69); novelas como Viaje al centro de la Tierra (1864) de Julio Verne o La Fundacion (1951) de Isaac Asimov. Sin adentrarnos en los orígenes de la ciencia ficción, nuestro interés es remarcar que tales historias fueron visiones futuras que mezclaban avances científicos con elementos del mundo conocido. Pero antes de llegar al mundo físico, incluso a ser plasmadas en papel o fotografía, fueron concebidas en nuestras mentes como imágenes/reales-vituales, y probablemente muchas de ellas en movimiento. Frank David, gran cineasta checo y escritor, contribuyó al mundo de la enseñanza con "el paradigma secuencial" (una historia se divide en secuencias) adaptación de la estructura narrativa de los 3 actos, heredada de Aristóteles, al mundo visual, tal y como el cerebro percibe y organiza la realidad fragmentada con un principio, desarrollo y final.

Para dar explicación sobre las cuestiones hasta el momento expuestas, hemos estructurado el artículo en los siguientes puntos: 1 El arte de observar y percibir: que analiza las conexiones y relaciones de la animación con la percepción creativa, la importancia de lo cognitivo y la conciencia en el proceso creativo, con el fin de justificar nuestra visión de la animación como medio de reflexión, productor de realidades (im)posibles. 2. Animación y cognición. Expone las observaciones obtenidas del estudio de la producción artística de creativos profesionales y el impacto de la observación de clips animados. De dichas experiencias y observaciones, siempre desde el punto de vista de la psicología y creación artística, llegamos al tercero: Usando la animación como reflexión, como el proceso y expresión consciente de emociones. En las conclusiones, abrimos una discusión y animamos tanto a creativos como a científicos, a estudiar y complementar su práctica profesional incluyendo la comunicación audiovisual, con el fin de profundizar en temas donde la animación puede aplicarse. En educación: empleando la inteligencia emocional para entender como vemos el mundo y a nosotros mismos. En ciencia: como la medicina; donde la animación puede ser un medio terapéutico en la enfermedad o para recrear cirugías virtuales antes de operar. Y dentro de la industria del cine: destacar el valor y las grandes aportaciones de la animación en las producciones audiovisuales por su gran poder de abstracción y trasgresión de la realidad hacia a mundos fantásticos.

Ante todo queremos mostrar la animación como un medio de comunicación y creación no solo de entretenimiento sino también de conocimiento: de gran utilidad en la educación, ciencias y medicina, por lo que es de gran interés profundizar en los mecanismos psicológicos que se ponen en funcionamiento cuando se crea o ve un film animado. Pues, seamos profesionales o no, tal y como se dice: "la vida es puro teatro" y las películas son reflejos de nuestros tácitos anhelos y realidades. Conviene saber entenderla para vivir una vida auténtica y no una farsa teatral, en donde se enmascaran las emociones: lo que conduce a la insatisfacción e incluso enfermedad. Cualquier realidad virtual es el mismo concepto/imagen que nace en nuestro cerebro: empezando por la observación (percepción) pasando por el racionamiento y transformación de la información (cognición) para su posterior expresión consciente en cualquier medio. Dichas fases se trabajan igualmente en el proceso creativo de un film animado o narrativa visual como escrita. 


\subsection{EL ARTE DE OBSERVAR Y PERCIBIR.}

¿Qué tiene que ver la animación con la observación? Mucho. Un buen animador-a es un gran observador.

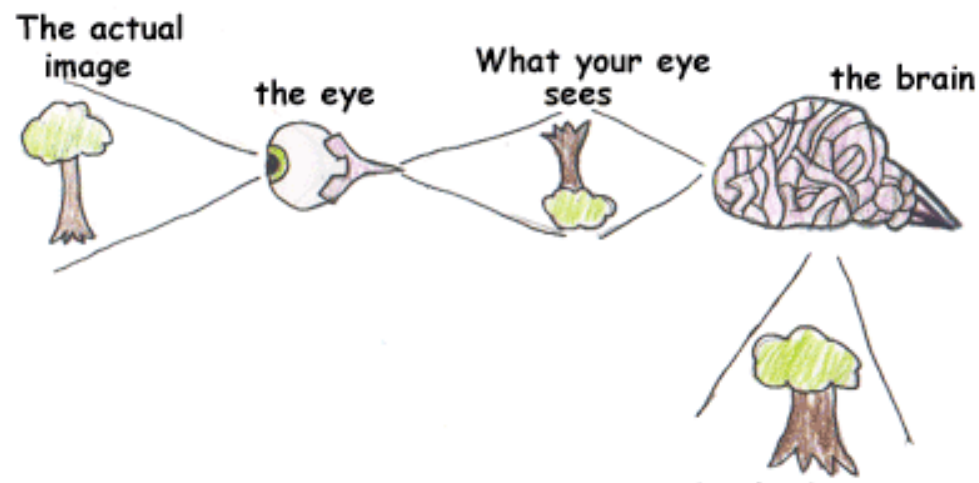

the final image

Ilustración 3. Cognitive science. April 18, 2012 [on line] http://cogsci.stackexchange.com/questions/337/why-would-the-brain-flipthe-images-perceived-by-your-eyes

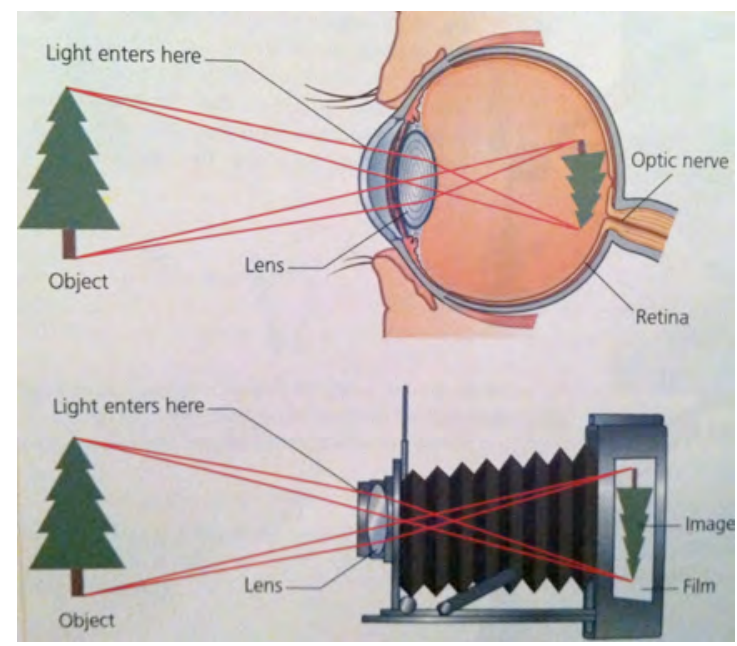

Ilustración 4. Camera-eye comparison. Discoverysolutions.com

Construimos a partir de lo que conocemos para inventar lo que (aún) desconocemos, lo virtual. Los animadores, como los alquimistas, al igual que cualquier creativo, somos los observadores científicos del mundo exterior e interior. Recolectores de información referencial que nuestro cerebro almacena, como piezas de un puzle a completar, con el fin de dotar de un sentido a la experiencia vivida. Los ojos son la cámara, y el cerebro es el editor de nuestra película; quien rellena los vacíos perceptuales, como si tuviera vida propia. ¿Podemos creer siempre que todo lo que vemos es real? ¿incluso lo que nuestros ojos no fueron capaces de ver en un determinado momento? No olvidemos que perdemos información en un pestañeo al igual que nuestra atención se reduce a una determinada área de interés, dejando el resto fuera de campo (b/ur) al igual que cuando leemos unas líneas y nuestros ojos enfocan solamente la parte que recorren. 


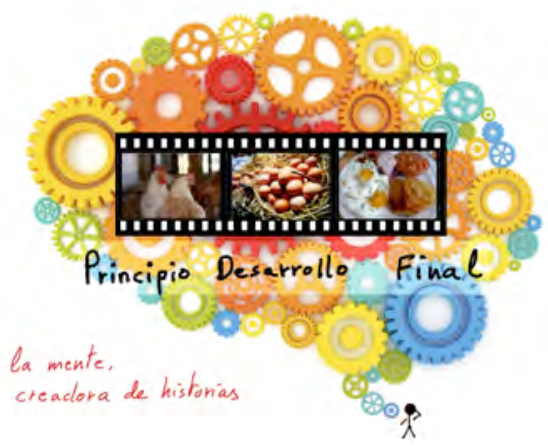

Ilustración 5 “Brain mechanism”. Remake. Carpe, Inma. http://pixshark.com/aprendizaje-cerebro.html

Jeffrey Zacks en su libro Flicker (2014) cuestiona donde está el límite que separa la ficción de lo real, ya que las películas simulan y crean emociones tan similares como en la vida misma, pudiendo llegar a confundirnos con falsos valores o imágenes. La sensación de tener que racionalizar lo que se ve para comprenderlo, parte de cómo percibamos la información y realicemos las conexiones entre dichas piezas del "puzzle", The interconnectedness of all things, Douglas Adam (2014) independientemente de la necesidad de la condición humana de controlar y prever el futuro para su estabilidad, pues como Robertson dijo:- "El ojo solo ve lo que la mente es capaz de comprender". (Davies, R. Año:pp)

Nuestro cerebro almacena imágenes como si de un gran storyboard se tratara. Zacks pone de manifiesto el gran conocimiento que los cineastas poseen sobre la percepción, cognición y emociones. Cada vez hay más directores de cine y doctores interesados en estudiar qué es lo que produce el éxito de una buena película. Todos coinciden en tener un buen guión, pero ¿qué es lo que conecta la audiencia con esa historia? Uri Hasson de la Universidad de Priceton ha creado el término Neurocinematics, la neurociencia del cine, donde la empatía es la llave que conecta la audiencia con el film. Cuando vemos una película o nos relatan una historia se produce lo que Hasson denomina sincronización de cerebros, uno siente lo que el narrador está contando como si fuera real al igual que lo imagina, en caso de no estar observándolo. Esto se debe a que el ser humano se siente identificado con el relato o personajes pues de algún modo en su cerebro, hay imágenes, memorias construidas de experiencias similares. Talma Hendler (Tel Aviv) es otra de los científicos que aplica el uso de films en el área de psiquiatría y psicología para obtener mayor conocimiento de las áreas del cerebro que se activan cuando se ve una película. Es otro modo de acercarse a la investigación del mundo emocional: principal motor de nuestro comportamiento, y tratar enfermedades mentales desde otros ángulos. De ahí que sintamos miedo, dolor o tristeza cuando vemos alguna escena dramática, sin olvidar del efecto espejo de nuestras neuronas, por el que imitamos lo que vemos (de manera inconsciente y/o consciente). Para que algo nos importe nos tiene que afectar emocionalmente, para creerlo, tenemos que sentirlo. Es la panacea que tanto busca la realidad virtual contemporánea. Pero antes de profundizar en la neurociencia del cine, fue Rudolph Arheim en su libro, "Arte y percepción visual" (1954) quien reveló las bases del entendimiento de cómo vemos el mundo en formas, colores, luces, etc., en especial los artistas. De hecho el libro se subtituló una psicología del ojo creativo. Antes de toda creación tenemos que observar, según como percibamos la realidad por nuestro ojo creativo, pasaremos a racionalizar la información mediante un proceso de aprendizaje dando lugar a los pensamientos, lo cognitivo, para transformarlos en expresiones animadas, cargadas de emoción. Descubrimos films desde lo más surrealista y tenebroso como Down to the Cellar de Jan Švankmajer (1983) y aunque no se trate de animación tradicional, es interesante por su plasmación de los temores inconscientes, plasmados a través de la percepción de una niña. Films simbólicos, Food (1992, Švankmajer); abstractos, The Dot and the Line: A Romance in Lower Mathematics de Chuck Jones, Maurice Noble (1965) Boogie-Doodle (1940, Norman Mclaren) o intentos hacia un hiperrealismo, como en Polar Express (2004) o Beowulf (2007) ambas de Robert Zemeckis.
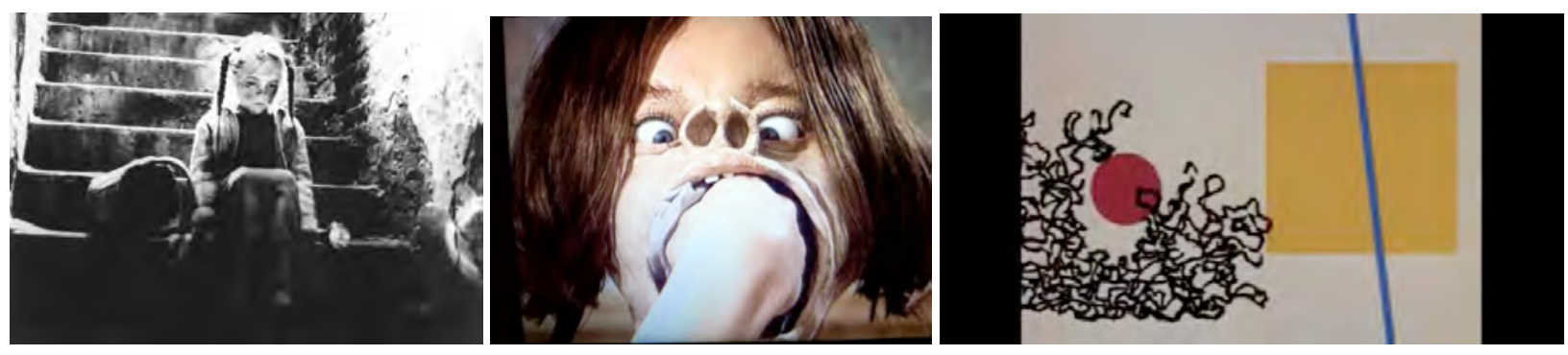

De izda. a dcha.: Ilustración 6. Down to the Cellar; llustración 7. Food; Ilustración 8. The Dot and the Line: A Romance in Lower Mathematics. 


\subsection{ANIMACIÓN Y COGNICIÓN.}

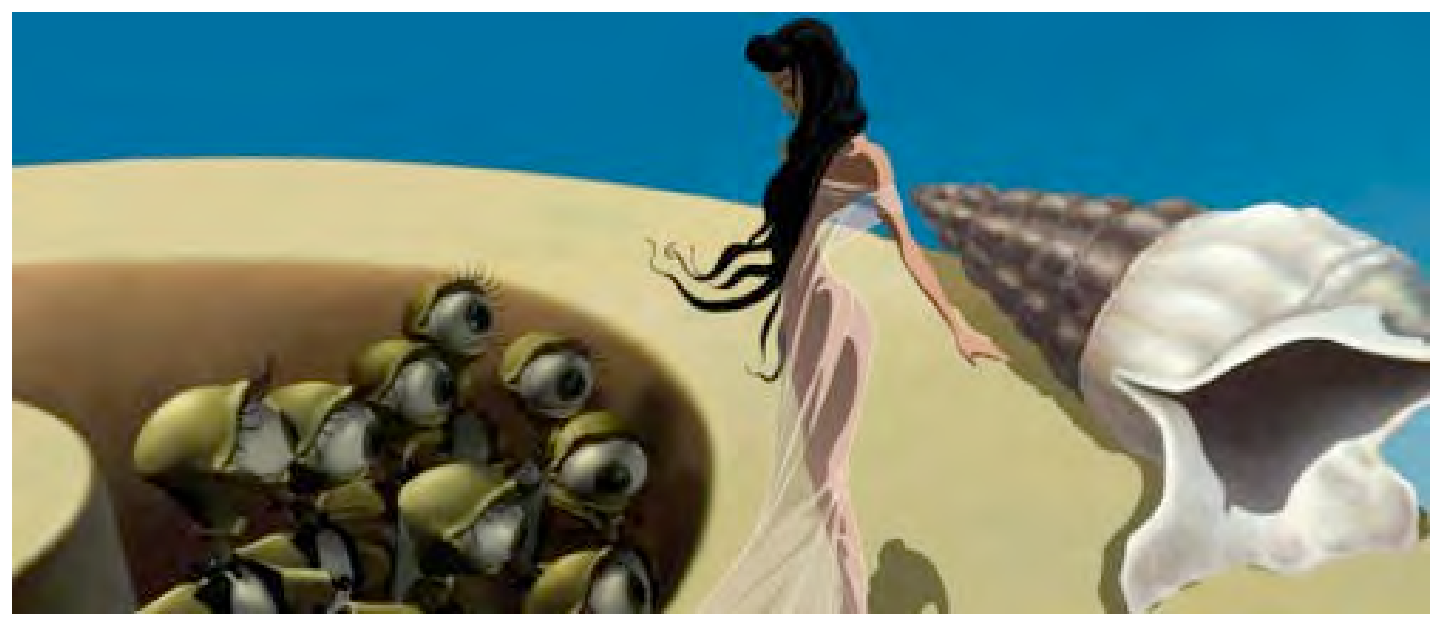

Ilustración 9. Destino. Walt Disney (2003)

El éxito de la animación reside en su nivel de abstracción como metáforas, haciéndola llegar a todo el mundo gracias a sus símbolos en forma de personajes animados, realistas o surrealistas. Un gran ejemplo es Destino, Disney (2003), producto de la colaboración entre Disney y Dalí. Según estos símbolos o formas se comporten, la audiencia creerá si un perro se comporta como un perro o una lámpara se comporta como un ser humano. Es por este poder de abstracción que nuestra mente es capaz de extrapolar características propias de una entidad y llevarlas a otra muy distinta (descontextualización) ofreciéndonos el deleite de creer una "virtual realidad", muy distinta a la que vemos a diario. En animación un niño puede ser un pez The Sword in the Stone (1963) una tetera puede hablar Beauty and the Beast (1991) ambas de Disney y los juguetes pueden hasta cobrar vida cuando no se les ven Aventuras en el ático, de Jiri Barta (2009) o Toy Story, John Lasseter $(1995,1999,2010)$ A través de la animación ejercitamos de manera consciente la observación de lo externo para su análisis posterior, de-construyendo esa realidad. Esto es posible gracias a los procesos cognitivos, los cuales, son procesos psicológicos que procesan la información del exterior, la organizan y la interpretan. Dichos procesos crean pensamientos, reflejos de lo que conocemos en la realidad, de esta manera, todos somos directores o actores de nuestras propias películas caseras, que nuestra mente crea a diario. Podemos observarlo en especial cuando recordamos algún evento o sujeto; al soñar, donde se mezclan rostros, lugares familiares y experiencias, o al imaginar. En muchos casos se perciben olores y sensaciones que nos hacen confundir lo auténtico de lo onírico, de no ser por el despertador- alertador del fin de la aventura; como ocurre en Abre los Ojos , A. Amenábar (1997). Los conceptos (imágenes) son ya una realidad virtual que nuestra mente genera antes de ser materializadas. Un gran ejemplo de controlar de manera consciente la información basada en la realidad cotidiana para reconstruirla es Inception, Christopher Nolan (2010). La animación es de gran ayuda para experimentar con la creatividad y explorar nuevos mundos sin límites, pues la imaginación no los posee, de no ser que uno los establezca. La tecnología es relevante, en ocasiones tanto, que hasta que no está suficientemente desarrollada no se desarrollan proyectos como Avatar (2009 J. Cameron), pero hay una inteligencia, y no artificial, que la conduce.

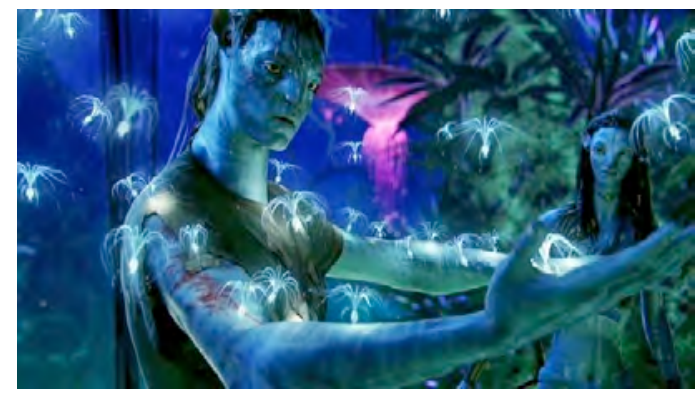

Ilustración 10. Avatar . James Cameron (2009) 


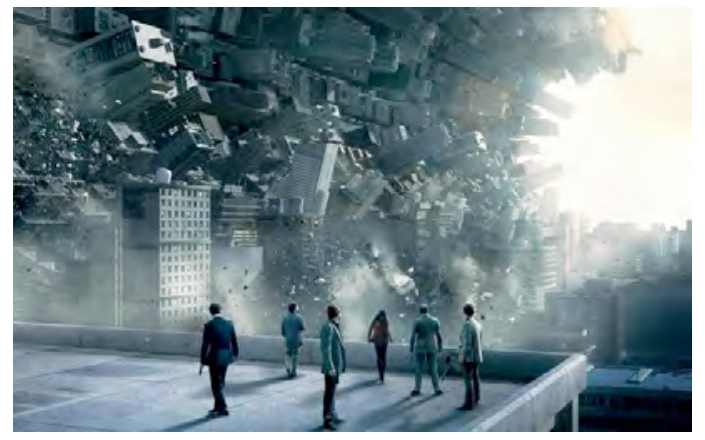

Ilustración 12. Inception. Christopher Nolan (2010)

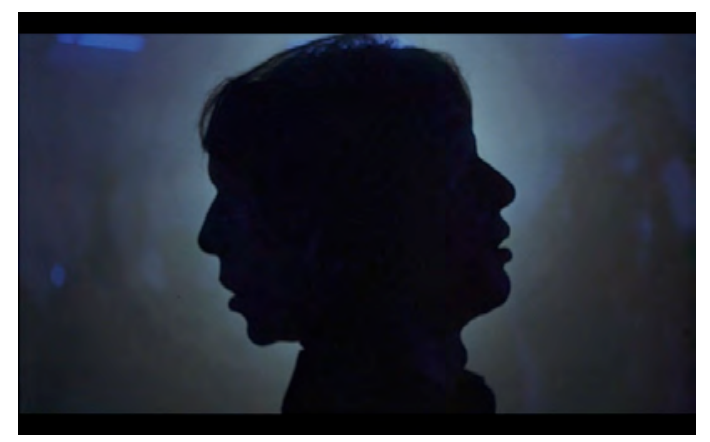

Ilustración 11. Abre los Ojos. A. Amenábar (1997)

\subsection{USANDO LA ANIMACIÓN COMO REFLEXIÓN, COMO EL PROCESO Y EXPRESIÓN CONSCIENTE DE EMOCIONES.}

En el cine de acción hay limitaciones físicas por las que se recurre a la animación (en especial 3D) para combinar la realidad de un escenario con elementos de ficción, pudiendo rozar y traspasar los límites de lo verosímil. Para que algo sea aceptado como real, se debe de sentir, y aquí entran en juego las emociones y su interpretación; que influyen en cómo vemos y aprendemos el mundo exterior. Los animadores, así como los actores han de representar una serie de comportamientos y sentimientos a través de sus acciones, por lo que deben de ser conscientes de sus emociones para saber llegar a trasmitirlas. La animación es un medio visual y sensorial del pensamiento. Los animadores son como los personajes animados de Desanimado Emilio Martí (2011) comedia donde el personaje cuestiona y animaliza sus emociones y percepción de la realidad.
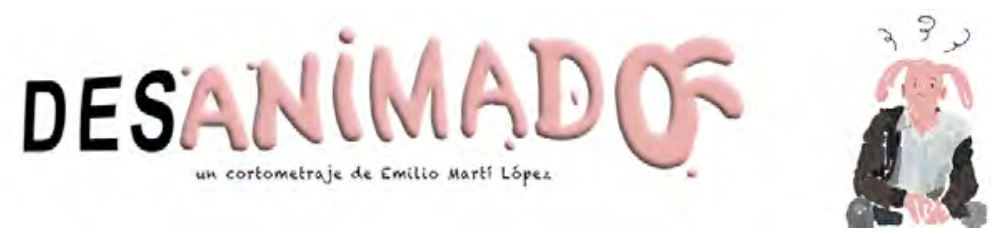

Ilustración 13. Desanimados. Emilio Martí (2011). IMDB. http://www.imdb.com/title/tt1980087/

A través de ejercicios de actuación es necesario gran concentración y atención al cuerpo para pensar como realizar los movimientos de acorde a la intención del personaje cuando actúa. De aquí que la práctica de mindfulness, sea efectiva en animación. Ed Hooks, actor y profesor de Acting for animators, es reconocido por sus cursos para animadores, donde trabaja las emociones y la psicología que la puesta en escena lleva a cabo.

El proceso creativo de un film animado comienza en primer lugar, con la atención. Como creadores, observamos el medio ambiente, recogemos información en fragmentos: sonidos, dibujos, fotografías, etc. que percibimos a través de los sentidos, para más tarde usarlas como referencias en la creación de personajes, historias o escenarios; sin olvidar de las emociones que se quieren (re)crear o transmitir ( preproducción). Tras el análisis, la información se convierte en conceptos o híbridos de realidades, los bocetos de guión. Como catarsis de la recopilación de datos y reorganización se pasa a la fase de producción, una vez se hayan discutido y concretado los diseños. Cada vez que se termina una escena, se reflexiona sobre el trabajo realizado, haciendo varios pases (o lecturas) para perfeccionar la película o animación, centrando la atención no solo en detalles técnicos sino también en la carga emotiva de la película o 
escena. Esta forma de trabajo estructurada en secuencias, se asemeja a los sistemas cognitivos en el que nuestro cerebro: obtiene información, la procesa y crea pensamientos, patrones conductuales o historias que luego soñamos, inventamos o simplemente reinventamos. Los estudios sobre narrativa visual (Dr. Paul Zack) junto a la emergente neurocinematics, ven los efectos de las películas en distintas áreas de nuestro cerebro. Si solamente viéndolas podemos sentir esas realidades virtuales, films, dichas sensaciones son mas presentes o conscientes cuando se es el realizador del film o el protagonista de una escena. Razones por las que apreciamos el proceso creativo audiovisual como herramienta de reflexión, de estudio de emociones y pensamientos que construyen nuestras realidades aplicables también como medio terapeútico: En 1962 Nag Ansorge (5) sugirió comprar una cámara de 16mm para los pacientes del Hospital Psiquiátrico de Cery, en Laussanne, Suiza. Su director, el profesor Müller se entusiasmó con la propuesta e inmediatamente comenzó un taller de producción de cine que se alargó 19 años, produciendo trece películas de entre 10 y 20 minutos de duración, de las cuales 8 fueron animadas.

Una mesa de animación fue construida por un paciente que había sido carpintero. La técnica de animación preferida era la de papel recortable. La técnica les permitió compartir el trabajo en grupo...Desde la primera película se demostró que el cine era un medio terapéutico excelente para estimular a los pacientes que tenían dificultades para relacionarse con los demás a salir de su caparazón y colaborar. El grupo discutía la secuencia de acciones, elegía un guión que se podría hacer, realizaba los dibujos, detalles y fondos, filmaba la animación cuadro a cuadro, lluminaba el set en el que se rodaría, elaboraba la película y la banda sonora y finalmente escribía un texto y lo grababa. (Ansorge, N., 1998.)

\section{CONCLUSIONES Y DISCUSIÓN.}

1. La animación ofrece un método de trabajo dinámico en el que se experimenta desde la libertad, diferentes roles que benefician al conocimiento y aprendizaje de las emociones y creencias, que los seres humanos adquieren desde su infancia. Se abren las puertas a cuestionar pensamientos propios y modos de percibir la realidad. Fomentando un enriquecimiento en el desarrollo personal y grupal.

2. Como un juego, la animación, por medio de la interpretación, ayuda a ser más conscientes de nuestras acciones y patrones conductuales (fuera y dentro de una película) así como poder trabajar en ellos.

3. El proceso creativo de animación, así como la narrativa visual, tiene similitudes con las principales partes del proceso psicológico de la percepción de la realidad.

4. La animación es punto de encuentro, donde las artes y ciencias pueden complementarse y ayudar a expandir sus limitaciones en busca de nuevos horizontes. En el proceso creativo de un film podemos apreciar un aumento de la creatividad debido a la colaboración e intercambio de información entre los diferentes miembros del equipo.

5. A través de la narrativa visual, la animación es el medio ideal para jugar con la imaginación y la creatividad, generando un espacio para concebir lo imposible debido a las limitaciones del mundo físico.

La animación es tanto medio como herramienta, donde las ideas se transforman en imágenes y los sueños en realidades en movimiento. El proceso creativo de un film animado por el que podemos contar una historia o situación bajo nuestra perspectiva, nos proporciona una visión fresca, donde podemos observar ideas y sentimientos propios o ajenos a modo de introspección: individual o colectiva, según cuantos creadores formen parte de esa realidad en construcción.

Nuestra identidad, individual y colectiva, se basa en el aprendizaje vivencial, por lo que es de gran relevancia poner atención y observar lo que hacemos y cómo lo hacemos, para una comprensión más rica en matices, flexible y tolerante. Realidades hay muchas, quizá unas más equilibradas que otras, pero todas parten de una verdad, una percepción que se ha de cuidar, como decía R. Arheim.-"toda percepción es pensamiento, todo razonamiento es también intuición, toda observación es también invención"-.

Es interesante continuar estudiando las películas y su proceso creativo, para ser aplicados en terapias psicológicas, cognitivas, en ciencia y educación. La animación ocupa aquí un papel relevante, no solo en las películas, sino también en la vida: como un medio de reflexión y puente para la re-creación de realidades que parecen im-posibles.

El cine no es un arte que filma vida, el cine está entre el arte y la vida. Jean Luc Godard 


\section{FUENTES REFERENCIALES.}

ADAMS, Douglas. Dirk Gently's Holistic Detective Agency. US. October 7, 2014. Gallery Books. ISBN 978-0-330-30162-6.

ANSORGE N., 1998. "Animated Films In Psychiatry. The Psychiatric Clinic of the University of Lausanne. Cery Hospital, 1962-1981", Animation World Magazine, Issue 3.2, May 1998. http://www.awn.com/mag/issue3.2/3.2pages/3.2ansorgeteachingeng.html

ARNHEIM, Rudoph. Visual Thinking. US. April 16, 2004. University of California Press, Ltd. ISBN 0-520-01871-0

ARTAUD, Antonio. "El teatro alquímico". Biblioteca virtual universal. 2006. Disponible en internet: http://www.biblioteca.org.ar/libros/300159.pdf

BUTTERFILL, A. Stephen. "Perceiving expressions of emotion: What evidence could bear on questions about perceptual experience of mental states? “.Elsevier. 2015. Consciousness and Cognition. journal homepage: www.elsevier.com/locate/concog

CASE, Laura K., PINEDA, Jaime., RAMACHANDRAN, S. Vilayanur . "Common coding and dynamic interactions between observed, imagined, and experienced motor and somatosensory activity”. Elsevier Ltd. Neuropsychologia. 3 April 2015. journal homepage: www.elsevier.com/locate/neuropsychologia

CANEMAKER, John. "Slipsliding Between Animation and Reality" [on line]. New York Times. November 24, 1996. Disponible en internet: http://www.nytimes.com/1996/11/24/movies/slipsliding-between-animation-and-reality.html?pagewanted=1 [consulted: May 04 2015]

CLARK, Rob. "Storytelling \& Neuroscience". [on line]. Slideshare. Feb 23, 2015. Disponible en internet: http://www.slideshare.net/theelusivefish/storytelling-andneuroscience-pcto [consulted: May 05, 2015]

DALLEY, T. 1987. El arte como terapia. Biblioteca de Psicología, Volumen 151. Herder.

DISPENZA, Joe. Breaking the Habit of Being Yourself: How to Lose Your Mind and Create a New One.1st ed. USA: Hay House, Inc. February 2012. ISBN: 978-1-4019-3810-9.

FERNÁNDEZ, Carlos F. "El cerebro, su función y cómo se forman los pensamientos, explica Rodolfo Llinás" [on line]. El Tiempo. Jueves 30 de abril de 2015. Disponible en internet: http://www.eltiempo.com/archivo/documento/CMS-4922448 [consulted: May 05 2015]

GOLEMAN, Daniel. SENGE, Peter. The Triple Focus: A New Approach to Education. 1st ed. US. July 31, 2014. More Than Sound. ISBN 978-1-934441-78-7.

GRAHAM, Danielle. "The Science of Interconnectedness". [on line]. Super Consciousness Magazine. Spring 2011. Disponible en internet: http://www.superconsciousness.com/topics/science/science-interconnectedness [consulted: May 05 2015]

GRUNDMANN, Uta. "The Intelligence of Vision: An Interview with Rudolf Arnheim”. [on line].Cabinet Magazine.2001.Issue 2. Disponible en internet: http://www.cabinetmagazine.org/issues/2/rudolfarnheim.php [consulted: May 04 2015]

GLEICHER, Michael. “Animation From Observation: Motion Capture and Motion Editing”. Computer Graphics. 33(4), p51-54. Special Issue on Applications of Computer Vision to Computer Graphics. University of Wisconsin, Madison.US.

MARANÓN, Gonzalo Álvarez . "Cómo las buenas historias pueden cambiar la química del cerebro de tu audiencia y moverla a la acción”. [on line]. El Arte de representar (EAP). 25 de Octubre de 2012. Disponible en internet:

http://www.elartedepresentar.com/2012/10/como-las-buenas-historias-pueden-cambiar-la-quimica-del-cerebro-de-tu-audiencia-ymoverla-a-la-accion/\# [consulted: May 05 2015]

MILLER, Greg. “Cinematic Cuts Exploit How Your Brain Edits What You See” [on line]. Wired Science. September 04, 2014. Disponible en internet: http://www.wired.com/2014/09/cinema-science-film-cuts/ [consulted: May 04 2015]

MIALL S. David. "Emotions and the Structuring of Narrative Responses" [on line]. Poetics Today. 2011 Volume 32, Number 2: $323-348$. Disponible en internet: http://poeticstoday.dukejournals.org/content/32/2/323.abstract [consulted: May 04 2015] 
P.CHIN, Nancy. "Teaching Critical Reflection Through Narrative Storytelling" [on line]. Michigan Journal of Community Service Learning. University of Rochester Medical Center, US. Summer 2004, pp. 57-63. Disponible en internet: http://hdl.handle.net/2027/spo.3239521.0010.305 [consulted: May 04 2015]

RAMACHANDRAN, V.S. The tell-tale brain. 1st ed. United Kingdom. Windmill books. 2012. ISBN 9780099537595.

REED, Poppy. "Dementia: The Importance of Storytelling". [on line]. Active Minds Uk. February 25, 2014. Disponible en internet: http://www.active-minds.co.uk/news/post/dementia-the-importance-of-storytelling/\#.VUJQIJNLMsJ]consulted: May 05 2015]

RODRÍGUEZ, Alejandro., REY. Beatriz., CIEMENTE. Miriam., WRZESIEN. Maja., AICANIZ. Mariano. “Assessing brain activations associated with emotional regulation during virtual reality mood induction procedures". [on line]. Science Direct. October, 132014 . Disponible en internet: http://www.sciencedirect.com/science/article/pii/S0957417414006290 [consulted: May 05, 2015]

SIEGEL,G. Daniel. Mindsight: the new science of personal transformation. USA. 2010. New York. Bantam Books. Bandom House, Inc. ISBN: 978-0-553-90710-0.

WILSON, Kristin. Bordwell, David. "Simplicity, clarity, balance: A tribute to Rudolf Arnheim”. [on line]. Observations on film art. June 15, 2007. Disponible en internet: http://www.davidbordwell.net/blog/2007/06/15/simplicity-clarity-balance-a-tribute-to-rudolf-arnheim/ [consulted: May 05 2015]

ZACKS, Jeffrey. 2014. Flicker. Your Brain on Moves. 1st ed. USA. Oxford University Press. 2015. ISBN-10: 0199982872.

NOTAS (centros de investigación)

-Neurocinematics . Uri Hasson (Princeton). http://psych.princeton.edu/psychology/research/hasson/

- Dynamic cognition laboratory . Jeff ZACKS. http://pages.wustl.edu/dcl/jeff-zacks

- Center for Investigating Healthy Minds. Richard Davidson. http://richardjdavidson.com/research/

VIDEOS

DISNEY, E. WALTER. Original E.P.C.O.T film (1966) SD full version. Mar 5, 2013.1966 Walt Disney Pictures.

"Future of Storytelling: Paul ZaK". [on line]. Future of storytelling. Feb 19, 2013. Disponible online:

https://www.youtube.com/watch?v=DHeqQAKHh3M [consulted: May 05, 2015]

"The mystery of storytelling: Julian Friedmann" . [on line]. TEDxEaling. Nov 27, 2012. Disponible online: https://www.youtube.com/watch?v=al3-KI4BDUQ [consulted: May 05, 2015]

"TOMORROWLAND Featurette - Vision of Tomorrow" . [on line]. Disney News from Stitch Kingdom. Apr 14, 2015. Disponible online: https://www.youtube.com/watch?v=cJLlg-kNbZo [consulted: May 05, 2015]

"Tomorrowland - US Teaser Trailer". [on line]. Disney Movie Trailers. Oct 9, 2014. Disponible online: https://www.youtube.com/watch?v=1k59gXTWf-A 